\section{Aplikasi Teknologi Nanoenkapsulasi sebagai Delivery System Fitobiotik Alami untuk Ternak}

\author{
Umi Maesaroh, Nanung Danar Dono, dan \\ Zuprizal
}

Departemen Nutrisi dan Makanan Ternak, Fakultas Peternakan, Universitas Gadjah Mada. Jl. Fauna No. 3 Bulaksumur, Yogyakarta 55281 Telp. +62-274-513363.

zuprizal@ugm.ac.id

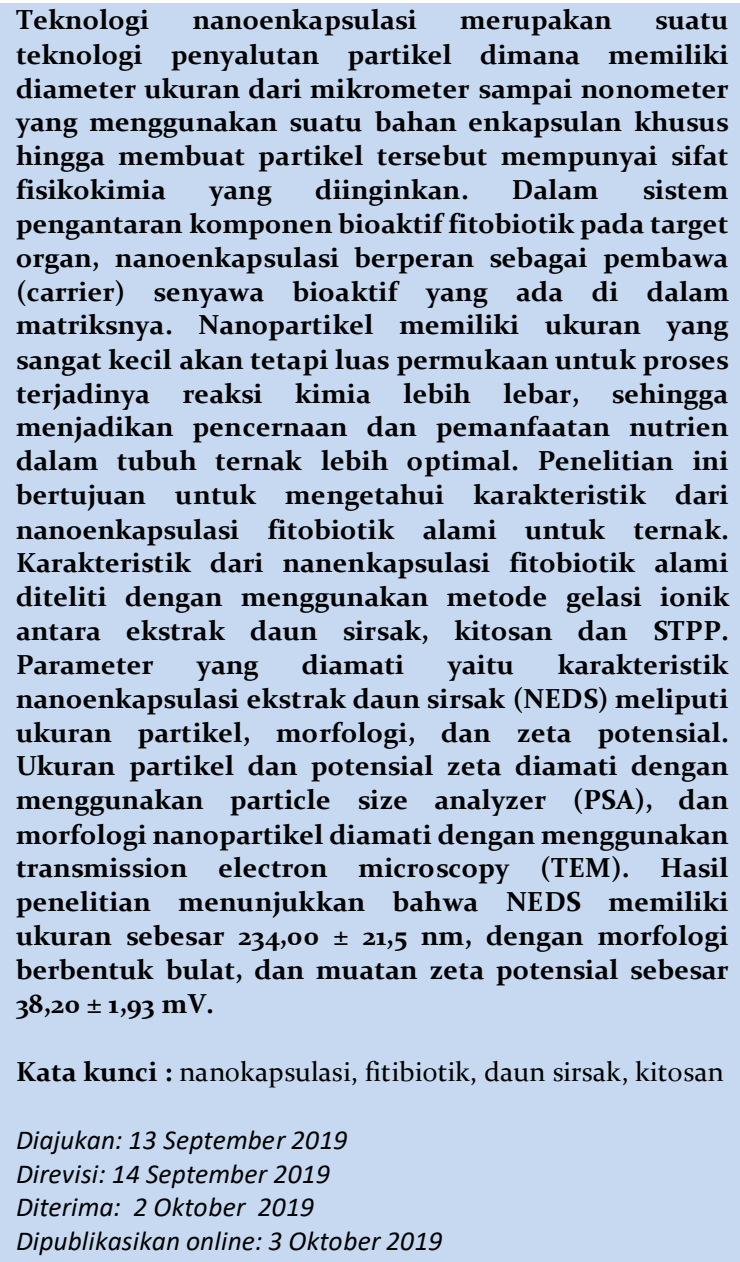

\section{Pendahuluan}

Antibiotik sudah umum sebagai growth promoters (AGPs) pada pakan ternak untuk meningkatkan produktivitas dan kesehatan ternak (Buchanan et al., 2008). Akan tetapi penggunaan antibiotik sebagai feed additive pada pakan ternak sudah dilarang karena dapat meninggalkan residu pada produk ternak yang dihasilkan. Pada bulan Januari 2018, secara resmi Pemerintah Indonesia telah melarang penggunaan antibiotik untuk ternak yang produknya dikonsumsi oleh manusia, melalui peraturan Menteri Pertanian (PERMENTAN) nomor 14/PERMENTAN/PK.350/5/2017 (Amalia dan Adisasmito, 2017). Penggunaan antibiotik secara terus menerus dalam jangka waktu yang panjang dapat mengakibatkan efek negatif berupa residu pada produk hasil ternak sehingga tidak aman untuk dikonsumsi. Oleh karena itu, diperlukan alternatif pengganti antibiotik yang dapat meningkatkan kesehatan saluran pencernaan dan dapat mengoptimalkan kinerja produksi ternak serta produk yang dihasilkan aman bagi konsumen.

Fitobiotik merupakan salah satu alternatif yang dapat digunakan sebagai pengganti antibiotik dan lebih aman untuk digunakan, karena tidak meninggalkan residu pada produk ternak yang dapat membahayakan konsumen. Fitobiotik atau yang dikenal dengan tanaman obat merupakan feed additive alami dari tumbuhan yang dapat meningkatkan pertumbuhan dan efisiensi pakan, mencegah oksidasi lemak, memperbaiki morfologi usus, serta dapat berfungsi sebagai antimikroba sehingga dapat meningkatkan daya tahan tubuh ternak (Hosseini et al., 2017). Salah satu fitobiotik alami yang dapat digunakan adalah ekstrak daun sirsak. Ekstrak daun sirsak ini mengandung senyawa metabolik sekunder seperti: flavonoid, tannin, fenol, dan alkaloid (Gavamukulya et al., 2014; Sugayana et al., 2016). Senyawa-senyawa tersebut memiliki kemampuan sebagai antibakteri alami dengan mekanisme berupa: menghambat sintesis asam nukleat, menghambat fungsi membran sel dan menghambat metabolisme energi.

Mekanisme aksi dari komponen bioaktif pada daun sirsak tidak dapat bekerja secara optimal di dalam saluran pencernaan karena bioaktif tersebut memiliki karakteristik berupa kelarutan yang rendah, cepat terdegradasi, bioavailabilitas yang rendah, dan cepat rusak oleh pengaruh lingkungan saluran pencernaan sehingga harus dilindungi dengan penstabil polimer nanoenkapsulasi yang dapat memproteksi komponen

Cara mensitasi artikel ini:

Maesaroh, U., Dono, N. D., Zuprizal (2019) Aplikasi Teknologi Nanoenkapsulasi sebagai Delivery System Fitobiotik Alami untuk Ternak. Buletin Profesi Insinyur 2(2) 091-095 
bioaktif tersebut (Esfanjani dan Jafari, 2016). Metode nanoenkapsulasi dapat melindungi komponen bioaktif dari pengaruh negatif lingkungan saluran pencernaan pada ternak, akan tetapi dalam formulasi pembuatan nanoenkapsulasi membutuhkan kajian tersendiri untuk menentukan perbandingan yang tepat antara ekstrak, kitosan dan STPP.

Salah satu metode yang dapat digunakan untuk pembuatan formulasi nanoenkapsulasi ekstrak daun sirsak adalah metode nanoenkapsulasi dengan gelasi ionik. Prinsip dari pembuatan nanoenkapsulasi dengan metode ini adalah terjadinya interaksi ionik antara gugus amin pada kitosan yang bermuatan positif dengan polianion yang bermuatan negatif (Sundari et al., 2014). Teknologi nanoenkapsulasi dibuat dengan proses gelasi ionotropik antara muatan negatif sodium tripolyphosphate (STPP) dan muatan positif gugus amin pada kitosan. Nanoenkapsulasi senyawa bioaktif dari ekstrak daun sirsak dengan metode gelasi ionik kitosan dan STPP diharapkan dapat mengoptimalkan mekanisme kerja dari masing-masing bioaktif sebagai antibakteri untuk menggantikan antibiotik yang digunakan sebagai feed additive untuk ternak.

\section{Metode}

Proses ektraksi

Tepung daun sirsak diekstraksi dengan menggunakan etanol 96\% dengan metode maserasi selama tiga hari $(1: 100 \mathrm{~s} / \mathrm{v})$. Hasil ekstraksi disaring dengan menggunakan kertas saring untuk menghilangkan partikel kasar yang tidak larut dalam etanol, kemudian dievaporasi pada suhu $60^{\circ} \mathrm{C}$ dengan menggunakan waterbath. Maserat yang diperoleh kemudian dilarutkan dalam $2 \%$ aquades.

\section{Proses nanoenkapsulasi}

Proses pembuatan formulasi nanoenkapsulasi menggunakan metode gelasi ionik dengan mencampurkan $2 \%$ ekstrak daun sirsak : $0,2 \%$ kitosan : 0,04\% STPP (1: $1: 0,01)$. Hasil ekstrak daun sirsak dengan $96 \%$ etanol ditambahkan dengan kitosan yang telah dilarutkan dalam 1,5\% asam asetat, diaduk menggunakan magnetic stirrer selama 30 menit. Kemudian ditambahkan $0,04 \%$ STPP yang telah dilarutkan dengan aquades dan diaduk menggunakan magnetic stirrer selama 30 menit (Sundari, 2014).

\section{Analisis distribusi ukuran partikel nanoenkapsulasi}

Metode yang digunakan untuk analisis distribusi ukuran partikel nanoenkapsulasi adalah metode Dynamic Light Scattering (DLS). Pengukuran dilakukan dengan scattering angle $90^{\circ}$ dan temperatur dari holder $24,8^{\circ} \mathrm{C}$. Hasil yang didapatkan berupa kurva data ukuran partikel dan Polydispersity Indek (PI) (Liang et al., 2017).

\section{Analisis morfologi NEDS}

Morfologi NEDS dianalisis dengan menggunakan TEM. Sebanyak satu tetes sampel NEDS diletakkan pada grid tembaga kemudian dilapisi dengan karbon dengan alat auto carbon coated selama 5 detik, kemudian dikeringkan pada suhu ruang. Grid tembaga dengan sampel NEDS dilapisi dengan $2 \%$ asam fosfotungstat dan kemudian diamati menggunakan TEM dengan percepatan tegangan $120 \mathrm{kV}$ dan magnifikasi 120.000 (Liang et al., 2017).

\section{Analisis zeta potensial}

Zeta potensial dianalisis menggunakan metode Dynamic Light Scattering (DLS), dengan PSA (Liang et al., 2017).

\section{Hasil dan Analisis}

Ukuran partikel Nanoenkapsulasi Ekstrak Daun Sirsak Ukuran partikel NEDS dengan perbandingan $1: 1: 0,01$ (kitosan : ekstrak : STPP) sebagaimana yang ditunjukkan pada Gambar 1 adalah sebesar 234,00 $\pm 21,5 \mathrm{~nm}$ (Gambar 1) dengan nilai indeks polidispersitas yang rendah, yaitu sebesar 0,42 $\pm 0,20$. Hasil tersebut sesuai dengan penjelasan Martien et al. (2012) serta Esfanjani dan Jafari (2016) bahwa nanopartikel merupakan partikel yang memiliki ukuran dibawah 1 mikron atau 1000 nanometer. Perera et al. (2015) menyatakan bahwa partikel dengan ukuran $<500$ nanometer memiliki kecepatan terbaik untuk dapat melewati mukosa usus sehingga dapat mengoptimalkan proses penyerapan dan meningkatkan bioavailabilitas di dalam saluran pencernaan. Katouzian dan Jafari (2016) juga menambahkan bahwa ukuran nanopartikel akan mempengaruhi distribusi dan pelepasan bioaktif yang dibawanya. Semakin kecil ukuran nanopartikel maka proses distribusi dan pelepasan bioaktif menjadi lebih cepat dibandingkan dengan ukuran nanopartikel yang lebih besar $(50>200>500)$.

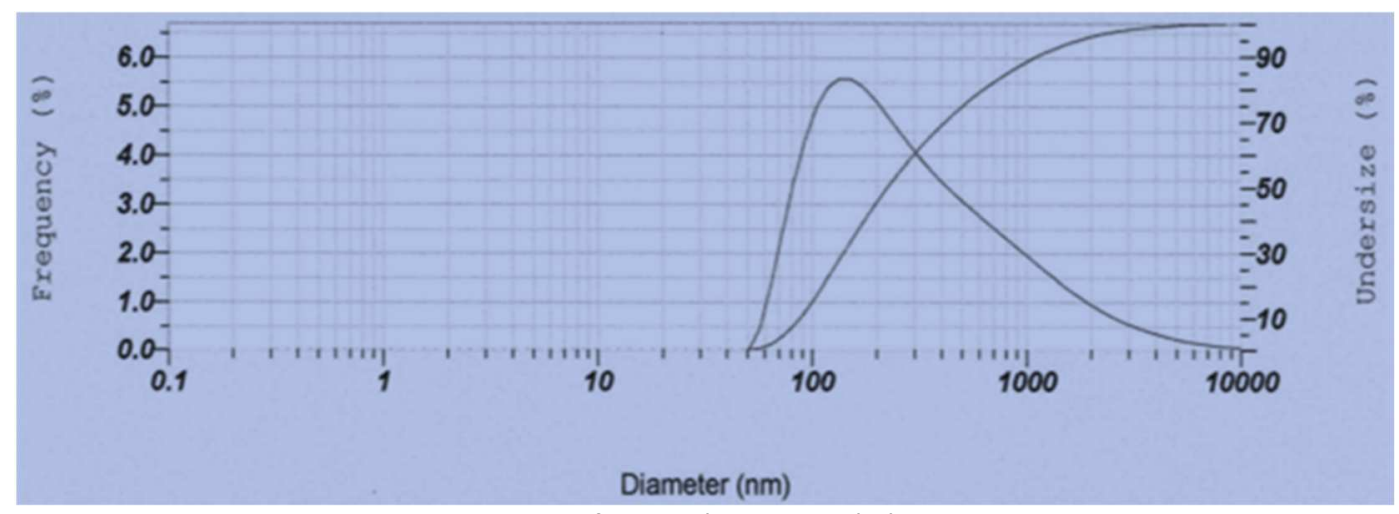

Gambar 1. Ukuran partikel NEDS 
Ukuran nanopartikel sebagai drug delivery system atau sistem penghantaran obat penting diperhatikan karena memengaruhi distribusi obat secara in vivo, tingkat toksisitas, kesesuain dengan target organ, muatan obat, proses pelepasan obat, serta stabilitas in vivo dan in vitro. Beberapa faktor yang mempengaruhi besar kecilnya ukuran nanopartikel sebagai penghantaran obat adalah ukuran dari polimer yang digunakan, proses formulasi, dan proses persiapan (Motiei et al., 2017). Al-Beitawi et al. (2016) menjelaskan bahwa nanopartikel memiliki ukuran yang lebih kecil akan tetapi memiliki luas permukaan untuk proses terjadinya reaksi kimia lebih lebar sehingga proses penghantaran obat menjadi lebih optimal di dalam tubuh ternak.

\section{Zeta potential}

Pengukuran zeta potensial dilakukan dengan menggunakan Particle Size Analyzer (PSA). Hasil pengukuran nilai zeta potensial dari nanoenkapsulasi ekstrak daun sirsak ditampilkan pada Gambar 2.

Berdasarkan hasil pengukuran dengan menggunakan PSA, nilai zeta potensial dari formulasi nanoenkapsulasi ekstrak daun sirsak yang dipilih adalah sebesar $+38,20 \pm 1,93 \mathrm{mV}$ (Gambar 2). Hasil ini sesuai dengan penelitian yang telah dilakukan oleh Dewandari et al. (2013) yang menunjukkan bahwa perpaduan antara kitosan dan STPP dalam proses gelasi ionik menghasilkan muatan zeta potensial positif. Hal ini disebabkan karena keberadaan gugus amin bebas yang mampu meningkatkan muatan zeta potensial dari nanopartikel yang dihasilkan. Pernyataan tersebut didukung oleh Rampino et al. (2013) yang menyatakan bahwa interaksi ionik dari muatan positif kitosan dan negatif STPP akan menghasilkan muatan utama adalah positif dari polianion kitosan. Motiei et al. (2017) menambahkan bahwa proses ionisasi dalam amino grup pada kitosan menyebabkan kationik yang dapat menghasilkan zeta potensial dengan nilai positif. Honary dan Zahir (2013) juga menjelaskan bahwa kitosan merupakan salah satu polimer bermuatan positif yang dapat berikatan dengan polymer yang bermuatan negatif untuk menghasilkan sistem penghantaran obat (drug delivery system) dengan tidak mempengaruhi kandungan fisikokimia dari obat tersebut. Kitosan digunakan sebagai pelapis nanopartikel dan menghasilkan muatan positif untuk memudahkan interaksi dengan sel mukosa yang memiliki muatan negatif.

Nilai zeta potensial dari nanoenkapsulasi ekstrak daun sirsak sebesar 38,20 $\pm 1,93 \mathrm{mV}$ menunjukkan hasil formulasi nanopartikel yang stabil. Hal ini sesuai dengan penjelasan Motiei et al. (2017) bahwa nilai zeta potensial absolut untuk nanopartikel yang menunjukkan kestabilan dan afinitas yang tinggi pada membran sel adalah $>25 \mathrm{mV}$. Servat-Medina et al. (2018) juga menjelaskan bahwa nilai zeta potensial yang kurang $-30 \mathrm{mV}$ atau lebih dari $30 \mathrm{mV}$ menunjukkan stabilitas partikel. Nilai zeta potential pada nanopartikel dipengaruhi oleh keberadaan gugus amino dan jenis muatan yang paling dominan dari beberapa polymer yang digunakan. Muatan zeta potensial terbaik dapat diperoleh dengan menentukan perbandingan formulasi yang tepat dari polymer yang memiliki muatan berlawanan. Muatan zeta potensial yang tepat membuat nanopartikel dapat dengan mudah menembus barrier mukus serta memudahkan terjadinya proses endositosis oleh sel endothelial sehingga menjadikan proses pelepasan obat lebih maksimal dan dapat dimanfaatkan dengan baik oleh target organ (Perera et al., 2015).

\section{Morfologi nanoenkapsulasi ekstrak daun sirsak}

Morfologi dari nanoenkapsulasi ekstrak daun sirsak diamati dengan menggunakan Trasmission Electron Microscopy (TEM). Hasil TEM dari nanoenkapsulasi ekstrak daun sirsak ditampilkan pada Gambar 3.

Morfologi dari nanoenkapsulasi ekstrak daun sirsak menunjukkan bentuk bulat seperti bola dan berwarna terang pada latar belakang gelap dengan ukuran yang homogen (Gambar 3). Hasil penelitian ini sesuai dengan penelitian yang telah dilakukan oleh Alves et al. (2016) dengan membuat nanoenkapsulasi asam galat yang dilihat menggunakan pengamatan Scanning Electron Microscopy (SEM) menghasilkan morfologi nanopartikel berbentuk bulat. Bentuk nanopartikel dari formulasi nanoenkapsulasi ekstrak daun sirsak yang bersifat non-agregat atau tidak menggumpal menunjukkan bahwa karakteristik nanopartikel stabil secara fisik (Badran et al., 2014).

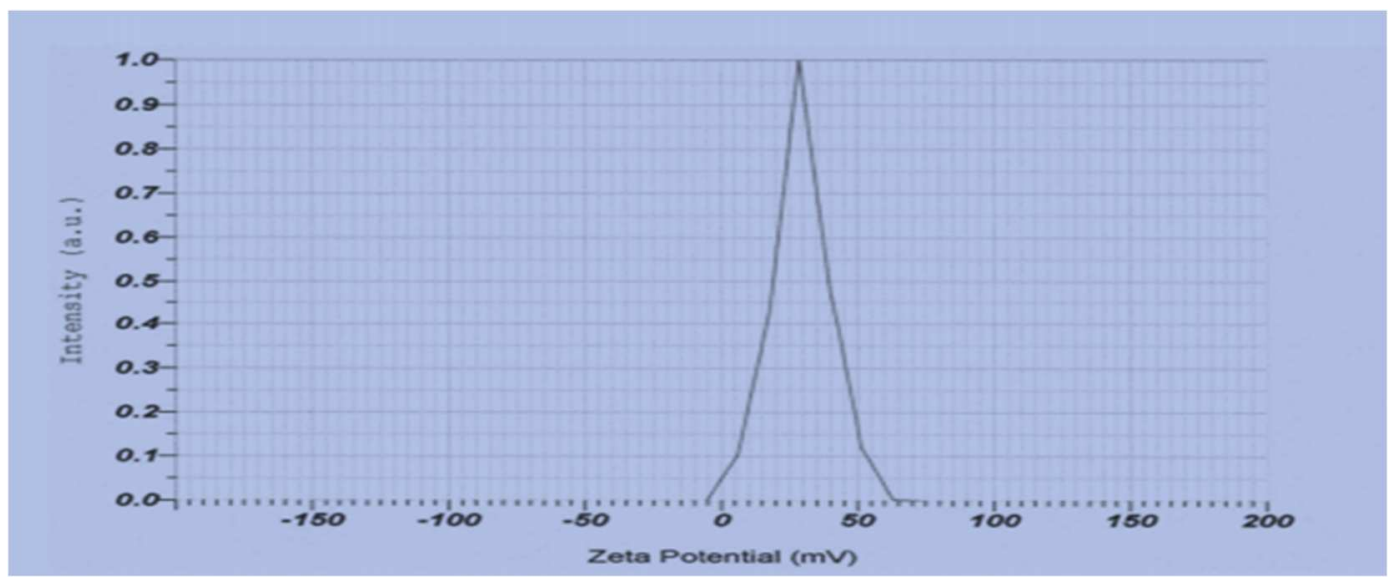

Gambar 2. Zeta potential NEDS 


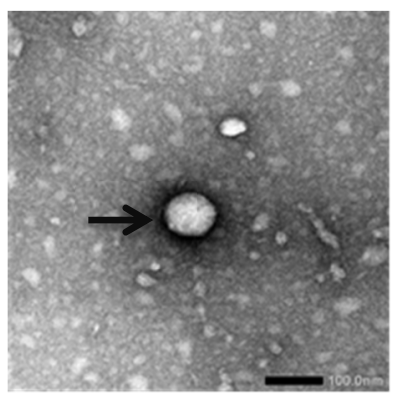

Gambar 3. Morfologi NEDS

Motiei et al. (2017) menyatakan bahwa nanopartikel terdiri dari polimer amfifilik yang mengandung senyawa hidrofobik yang terkumpul dibagian inti dan senyawa hidrofilik yang mengelilingi partikel tersebut sehingga mencegah dari pemisahan. Kitosan dan STPP merupakan polimer amfifilik yang mampu mengasilkan formulasi nanoenkapsulasi dengan ukuran partikel stabil, dan bentuk morfologi yang kompak (Rampino et al., 2013). Morfologi nanopartikel penting untuk diketahui karena bentuk partikel yang kurang sferis akan mempermudah kontak antar partikel yang dapat mengakibatkan agregasi sehingga dapat membuat nanopartikel tidak stabil (Martien et al., 2012). Alves et al. (2016) menyatakan bahwa setelah proses enkapsulasi yang terjadi antara kitosan, ekstrak dan STPP maka tidak ada lagi proses interaksi antara polymer penyalut dengan bioaktif di dalamnya.

Sediaan cair nanoenkapsulasi ekstrak daun sirsak

Sediaan cair dari nanoenkapsulasi ekstrak daun sirsak diformulasi dengan menggunakan metode gelasi ionik antara ekstrak daun sirsak, kitosan dan STPP yang ditampilkan pada Gambar 4.

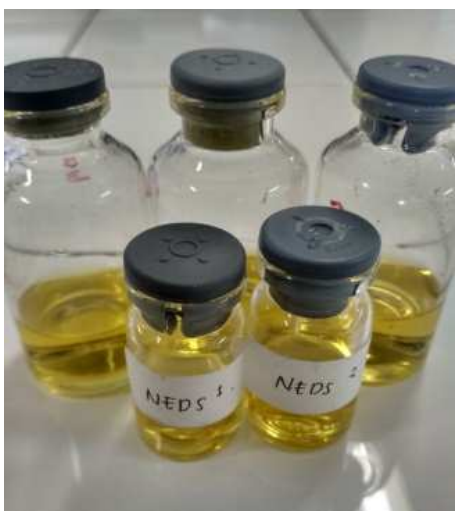

Gambar 4. Sediaan cair NEDS

Target khusus dari penelitian ini adalah untuk memperoleh formulasi yang tepat pada proses pembuatan nanoenkapsulasi ekstrak daun sirsak dengan karakteristik yang tepat, memperoleh produk teknologi tepat guna dalam inovasi pembuatan sediaan cair nanoenkapsulasi ekstrak daun sirsak dan pada penelitian tahap selanjutnya mengkaji tentang pengaruh penggunaannya secara in vivo pada ternak ayam broiler. Dengan demikian penelitian terobosan aplikasi nanoenkapsulasi ekstrak daun sirsak sediaan cair sebagai antibakteri alami untuk menghasilkan produk hewani dari ayam broiler yang bebas residu antibiotik, aman dan sehat, ini original dan belum ada yang meneliti serta sangat perlu dilakukan guna pengembangan ilmu pengetahuan (iptek), peningkatan efektivitas dan efisiensi produksi.

\section{Kesimpulan}

Penggunaan teknologi nanoenkapsulasi ekstrak daun sirsak dapat dilakukan dengan menggunakan metode gelasi ionik dengan memanfaatkan perbedaan muatan antara kitosan STPP, dan menghasilkan ukuran sebesar $234,00 \pm 21,5 \mathrm{~nm}$, dengan morfologi berbentuk bulat, dan memiliki muatan zeta potensial sebesar 38,20 \pm $1,93 \mathrm{mV}$, yang menandakan bahwa formulasi tersebut bersifat stabil dan homogen sehingga potensial untuk digunakan sebagai sistem penghantaran obat dari bioaktif yang ada di dalam ekstrak daun sirsak.

\section{Ucapan Terimakasih}

Penulis mengucapkan terima kasih kepada Laboratorium Teknologi Farmasi, Universitas Islam Indonesia dan Laboratorium IImu Makanan Ternak, Departemen Nutrisi dan Makanan Ternak, Fakultas Peternakan, Universitas Gadjah Mada Yogyakarta yang telah menyediakan fasilitas untuk penelitian ini. Kami juga ingin menyampaikan terima kasih kepada Kementerian Riset, Teknologi, dan Pendidikan Tinggi Republik Indonesia atas pendanaan untuk pelaksanaan dari penelitian ini.

\section{Referensi}

Buchanan, N.P., J.M. Hott, S.E. Cutlip, A.L. Rack, A. Asamer, and J.S. (2008) Moritz, The effects of a natural antibiotic alternative and a natural growth promoter feed additive on broiler performance and carcass quality, The Journal of Applied Poultry Research 17: 202-210.

Amalia, Z. and W. Adisasmito, (2017) Analysis of policy making factors on the prohibition of hormones and antibiotics use for feed as a public health protection, Journal of Indonesian Health Policy and Administration 2: 14-19.

Hosseini, S., M. Chamani, A. Seidavi, A.A. Sadeghi, and Z. Ansari-Pirsareai, (2017) Effect on feeding Thymolina $^{\circledR}$ powder in the carcass characteristics dan morphology of small intestine of Ross 308 broiler chickens, Acta Scientiarum 39: 45-50.

Gavamukulya, Y., F. Aboi-Elella, F. Wamunyokoli, and H. AEI-Shemy, (2014) Phytochemical screening, antioxidant activity dan in vitro anticancer potential of ethanolic dan water leaves extracts of Annona muricata (Graviola), Asian Pacific Journal of Tropical Medicine 7: S355-S363.

Sugayana, M., M. Magela, and G. Rubalakshmi, (2016) New Era about treatment-evaluation of anticancer properties of evergreen medicinal plant Annona muricata (Graviola), International Journal of Recent Scientific Research 7: 10954-10956.. 
Esfanjani, A.F., and S.M. Jafri, (2016) Biopolymer nanoparticles and natural nano-carriers for nanoencapsulation of phenolic compounds, Colloids and Surfaces B: Biointerfaces 146: 532-543.

Sundari, Zuprizal, T. Yuwanta and R. Martien, (2014) The effect nanocapsule of turmeric extracts in rations on nutrient digestibility of broiler chickens, Animal Production 16: 107-113.

Liang, J., H. Yan, X. Wang, Y. Zhou, X. Gao, P. Puligundla, and X. Wan, (2017) Encapsulation of epigallocatechin gallate in zein/chitosan nanoparticles for controlled applications in food systems, Food Chemistry 231: 19-24.

Martien, R., A. Adhyatmika, V. Farid dan D.P. Sari, (2012) Technology developments nanoparticles as drug delivery systems, Majalah Farmaseutik 8: 133-144.

G. Perera, M. Zipser, S. Bonengel, W. Salvenmoser, and A. Bernkop-Schnürch, (2015) Development of phosphorylated nanoparticles as zeta potential inverting systems, European Journal of Pharmaceutics and Biopharmaceutics 97: 250-256.

Katouzian, I. and S.M. Jafari, (2016) Nano-encapsulation as a promising approach for targeted delivery and controlled release of vitamins, Trends in Food Science \& Technology 53: 34-48.

Al-Beitawi, N.A., M.M. Shaker, K.N. El-Shuraydeh, and J. Blaha, (2017) Effect of nanoclay minerals on growth performance, internal organs and blood biochemistry of broiler chickens compared to vaccines and antibiotics, Journal of Applied Animal Research 45: 543-549.

Dewandari, K.T., S. Yuliani, and S. Yasni, (2013) Extraction and characterization nanoparticle red betel leaf
(Piper crocatum), Indonesian Journal of Agricultural Postharvest Research 10: 58-65.

Rampino, A., M. Borgogna, P. Blasi, B. Bellich, A. Cesàro, (2013) Chitosan nanoparticles: Preparation, size evolution and stability, International Journal of Pharmaceutics 455: 219-228.

Motiei, M., S. Kashanian, L.A. Lucia., M. Khazaei, (2017) Intrinsic parameters for the synthesis and tuned properties of amphiphilic chitosan drug delivery nanocarriers, Journal of Controlled Release 260 (2017): 213-225.

Honary S., and F. Zahir, (2012) Effect of zeta potential on the properties of nano-drug delivery systems -a review (Part 2), Tropical Journal of Pharmaceutical Research 12: 265-273.

Servat-Medina L, A. González-Gómez, F. Reyes-Ortega, I.M.O. Sousa, N.C.A. Queiroz, P.M.W. Zago, M.P. Jorge, K.M. Monteiro, J.E. de Carvalho, J.S. Román, and M.A. Foglio, (2015) Chitosan-tripolyphosphate nanoparticles as Arrabidaea chica standardized extract carrier: synthesis, characterization, biocompatibility, and antiulcerogenic activity, International Journal of Nanomedicine 10: 38973909.

Alves, A.C.S., R.M. Mainardes, and N.M. Khalil, (2016) Nanoencapsulation of gallic acid and evaluation of its cytotoxicity and antioxidant activity, Materials Science and Engineering 60: 126-134.

Badran, M.M., E.I. Taha, M.M. Tayel, and S.A. Al-Suwayeh, (2014) Ultra-fine self nanoemulsifying drug delivery system for transdermal delivery of meloxicam: dependency on the type of surfactants, Journal of Molecular Liquids 190: 16-22. 